\title{
Effect of Raw Material Composition on the Mineral Phases in Lime-fluxed Iron Ore Sinter
}

\author{
Li-Heng HSIEH and J. A. WHITEMAN ${ }^{1)}$
}

R\&D Department, China Steel Corporation, Kaohsiung, 81233, Taiwan. The University of Sheffield, Sheffield, S1 4DU, U.K.

1) Department of Engineering Materials,

(Received on October 30, 1992; accepted in final form on January 22, 1993)

\begin{abstract}
In this study small tablet specimens of powdered commercial iron ores mixed with fluxes and kaolin were heated in a reducing atmosphere and then cooled slowly in air to simulate industrial sintering. The effect of different ore and flux compositions on the phases found in the sinter bond was studied.

An increase in basicity $\left(\mathrm{CaO} / \mathrm{SiO}_{2}\right)$ favoured the formation of calcium ferrite and densification of the bond at a low sintering temperature. The amount of calcium ferrite decreased as the $\mathrm{Al}_{2} \mathrm{O}_{3}$ content decreased and the amount of reoxidized hematite produced on cooling decreased. $A$ decrease in $\mathrm{Al}_{2} \mathrm{O}_{3}$ content promoted a densification of the bond.

An increase in $\mathrm{MgO}$ content, introduced by addition of dolomite, decreased the amount of calcium ferrite slightly. When $\mathrm{MgO}$ was added in the form of serpentine the calcium ferrite content increased considerably. Increase in $\mathrm{MgO}$ markedly reduced the amount of reoxidized hematite but produced a less dense bond.

Generally the same composition and sintering temperature produced similar mineral compositions in the bond independent of the iron ore used. The only exception was when an ore with coarse dense hematite was used, in which case the bond contained some unreacted hematite. The porosity of the bond did vary with the type of ore used. Limonitic ore produced a bond with closed pores and less reoxidized hematite at lower temperature and basicity than did hematite ores.
\end{abstract}

KEY WORDS: agglomeration; sintering; iron ore; simulation; mineral phases.

\section{Introduction}

The properties of iron ore sinter are controlled by the composition and distribution of the mineral phases present. Therefore the effects of raw materials upon the minerals formed in sinter have been extensively investigated by experiments in which raw material tablets were heated in air to simulate industrial sintering. ${ }^{1-4)}$ In industrial sintering the raw materials are heated in a reducing atmosphere and then cooled in an oxidizing atmosphere. The authors ${ }^{5,6)}$ have found that the gas atmosphere used in sintering has a significant effect on the mineral phases that are formed. During heating of the sinter mix under a reducing atmosphere calcium ferrite dissociates into magnetite, the silicate melt and oxygen, whereas under a high oxygen potential it dissociates to form hematite and the silicate melt. When cooled in air the magnetite formed during heating may react with the silicate melt and oxygen to form calcium ferrite or else oxidize to hematite. The hematite does not tend to react with the silicate melt to generate calcium ferrite. Because of the importance of the gas atmosphere to the formation of the mineral phases in sinter the previous work which used only air may not relate well to industrial sintering.

The authors have shown in a previous study ${ }^{5}$ that heating a tablet of the appropriate raw materials in a reducing atmosphere and then cooling in air provides a reasonable simulation of industrial sintering. In industrial sintering the fine particles adhered on coarse ores are reacted to form the sinter bond. In this investigation the same simulation experimental method is used to determine the effect of ore and flux of different compositions upon the mineral phases produced in the bond during sintering. The results are compared with those produced by conventional sintering.

\section{Experimental Procedure}

\subsection{Raw Material and Tablet Preparation}

Table 1 shows the chemical composition and size of the raw materials used in this study. All the ores with the exception of ore $\mathrm{E}$ were hematite, ore $\mathrm{E}$ was limonitic. Each ore was screened or crushed to obtain a particle size smaller than $0.25 \mathrm{~mm}$ before use. The raw material mixtures which gave various chemical compositions of sinter were made into tablet specimens for sintering experiments. The ratio of each raw material in the mixture was calculated by use of a simple mass balance program.

Cylindrical tablets $6 \mathrm{~mm}$ in diameter and approximately $6 \mathrm{~mm}$ in height were produced by pressing $0.4 \mathrm{~g}$ 
Table 1. The information of raw materials.

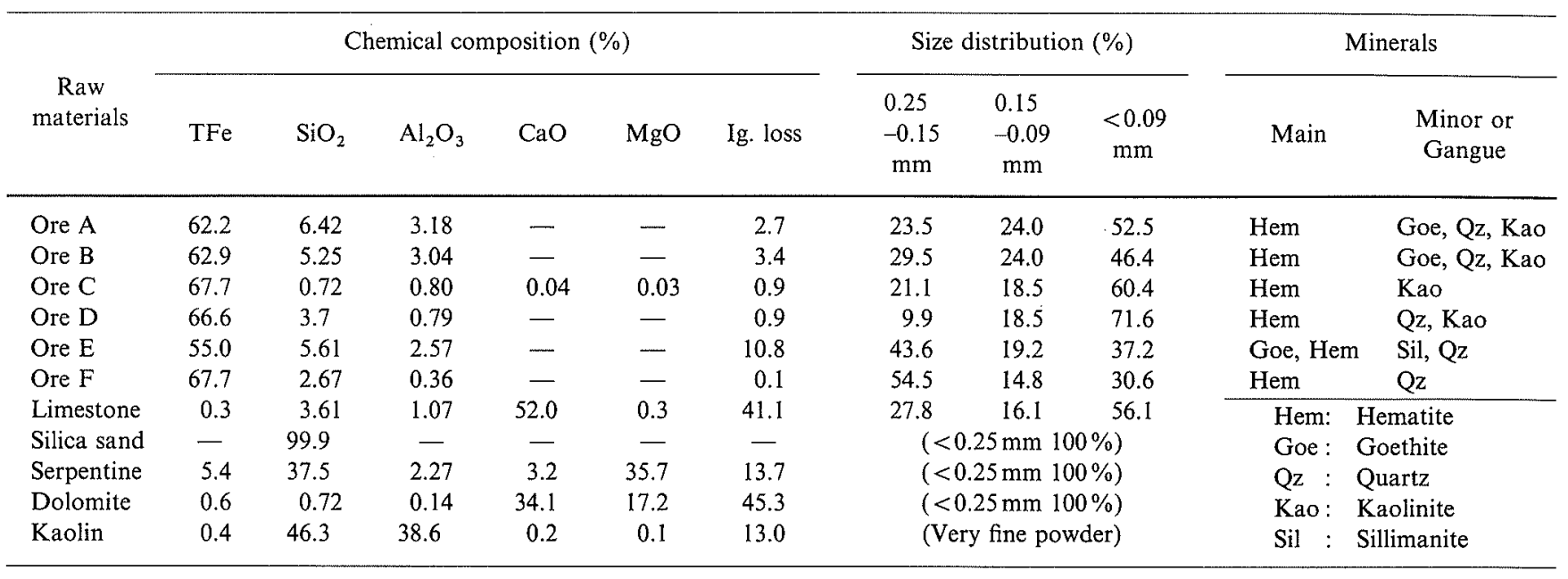

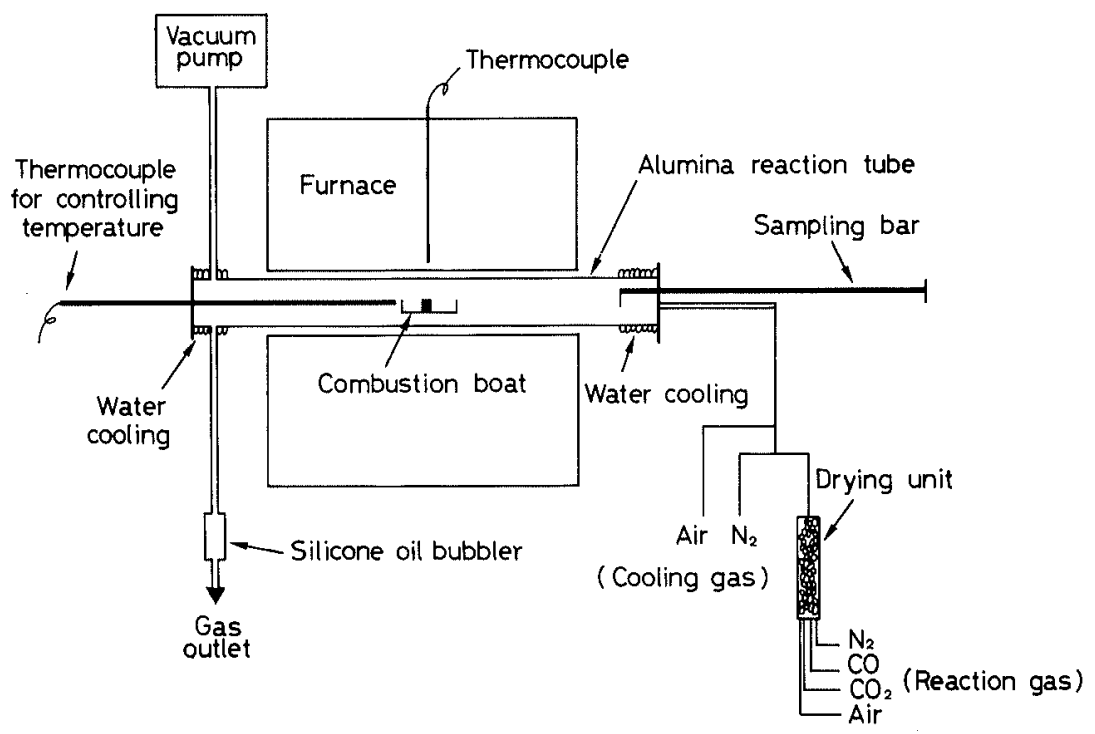

Fig. 1.

Sintering apparatus.

of raw material mixture bonded with $8 \%$ water into a cylindrical mould for $1 \mathrm{~min}$. A pressure of 0.45 $\mathrm{kg} / \mathrm{mm}^{2}$ was applied by a vertical loaded piston. Before the tablet was used for sintering it was dried at $110^{\circ} \mathrm{C}$ for $3 \mathrm{~h}$.

\subsection{Sintering}

The sintering apparatus was the same as that used in the authors' previous study ${ }^{5,6)}$ and is shown in Fig. 1. It consists of a tube furnace in which a gas mixture was passed through the alumina reaction tube $(25.4 \mathrm{~mm}$ diameter by $700 \mathrm{~mm}$ long) to control the sintering atmosphere. The furnace was kept at a predetermined temperature for any experiment. The specimen was placed in a small fireclay combustion boat some $72 \mathrm{~mm}$ long by $16 \mathrm{~mm}$ wide by $10 \mathrm{~mm}$ deep. This was pushed into the hot zone of the furnace; the specimen was at $290 \mathrm{~mm}$ away from the end of reaction tube. After the boat had been in the furnace for the desired time it was withdrawn and could be cooled in two different ways. Rapid cooling was achieved by withdrawing the boat into an unheated region of the tube surrounded by a water cooling coil. The cooling rate of specimen itself was approximately $750^{\circ} \mathrm{C} / \mathrm{min}$ in the first minute. Slow cooling entailed an intermediate hold at $1140^{\circ} \mathrm{C}, 170$ or $180 \mathrm{~mm}$ away from the end of reaction tube with the maximum sintering temperature 1250 or $1210^{\circ} \mathrm{C}$, for $2 \mathrm{~min}$ before removal to the cool region in the tube. The temperature in the tube was controlled by a $\mathrm{Pt} / \mathrm{Pt}-13 \% \mathrm{Rh}$ thermocouple held at $10 \mathrm{~mm}$ from the combustion boat. The temperature profile in the tube and sample for a given control temperature had been measured. The sintering temperature was the mean of that measured at the specimen top surface and that $1 \mathrm{~mm}$ below the top surface of the specimen. Typical heating and cooling curves for two sintering temperatures are shown in Fig. 2.

During the experiment the atmosphere was controlled by passing a gas mixture into the reaction tube. The gases used were $\mathrm{CO}, \mathrm{CO}_{2}, \mathrm{~N}_{2}$ and air. Gas from cylinders of the individual gases was passed through a drying tube $(500 \mathrm{~mm}$ long and $30 \mathrm{~mm}$ in diameter) filled with $\mathrm{CaSO}_{4}$ as a dessicant. The total gas flow rate was typically $400 \mathrm{~m} l / \mathrm{min}$ and the flow rate of the individual gases was measured by use of individual flow meters. To obtain a particular controlled atmosphere in the furnace, the tube was initially evacuated and the gas mixture was passed through the tube for at least $8 \mathrm{~min}$ 
before the specimen was pushed into the reaction zone. The cooling gas, $300 \mathrm{ml} / \mathrm{min}$, was either air or $\mathrm{N}_{2}$ and this was led directly through a gas pipe, $7.2 \mathrm{~mm}$ diameter by $900 \mathrm{~mm}$ long, into the reaction tube some $20 \mathrm{sec}$ before the end of the heating period to compensate for the time taken for gas to reach the specimen. The lead time is on the basis of the calculation for the change in gas composition at the place where the specimen is located. The exhaust gas was passed out of the reaction tube through a bubbler containing silicone oil.

Previous work ${ }^{5)}$ had shown that a gas mixture of $\mathrm{CO}=1 \%, \mathrm{CO}_{2}=24 \%$, and $\mathrm{N}_{2}=75 \%$ during heating followed by slow cooling in air closely simulated industrial sintering. This mixture was used as the standard for most of the experiments reported here. A few tests were performed with other gas mixtures and the mixtures used will be defined when the experimental results are presented. Rapid cooling enables the minerals present at the end of heating to be preserved and the changes induced during cooling can then be studied. It had been also applied in the previous work. ${ }^{5)}$

\subsection{Microstructural Analysis}

After sintering, the specimens were mounted in epoxy resin and vacuum impregnated. Generally the specimens were polished to provide a planar section $1 \mathrm{~mm}$ below and parallel to the original top surface of the pellet. These sections were polished by using silicon carbide paper to 1000 grit using ethanol as a lubricant. A final polish to $0.25 \mu \mathrm{m}$ was obtained using diamond paste. Care was taken to keep the specimen free from water throughout the whole process. The specimens were examined using a light microscope in reflection. The volume proportions of phases in sinter were estimated by using the point counting method. Around 1000 points were counted for the whole polished surface of a specimen. The volume proportions of each phase were calculated as follows:

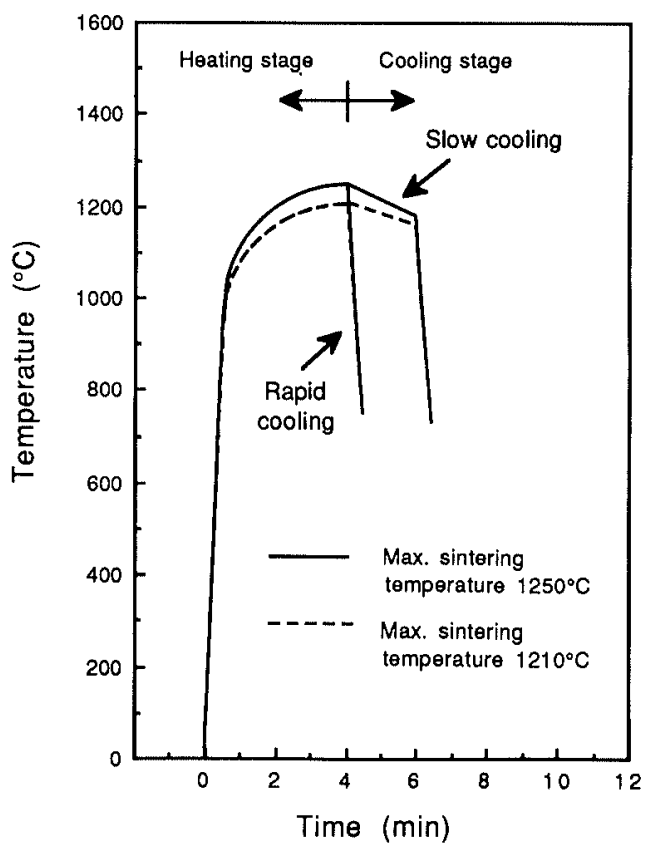

Fig. 2. Typical temperature/time profiles of sintering experiments.
Volume proportion of $\alpha$ phase $(\%)=$

$$
\frac{\text { Points of } \alpha \text { phase }}{\text { Total points of all phases }} \times 100(\%)
$$

Porosity $(\%)=$

$$
\frac{\text { Points of pores }}{\text { Total points of all phases + Points of pores }} \times 100(\%)
$$

\section{Results}

\subsection{Effect of Basicity on Mineral Phases}

Tablets made from mixtures containing ore $\mathrm{C}$ were heated in the standard gas mixture and then cooled slowly in air to simulate the formation of sinter bond in industrial sintering. Results for the proportions of mineral phases are shown in Fig. 3 as a function of basicity. The basicity $\left(\mathrm{CaO} / \mathrm{SiO}_{2}\right)$ ranges from 1.3 to 2.1 for a $\mathrm{CaO}$ content in the sinter bond of $10.5 \%$. A narrower range of basicity 1.7 to 2.1 was covered at a $\mathrm{CaO}$ content of $13.5 \%$. An approximately linear

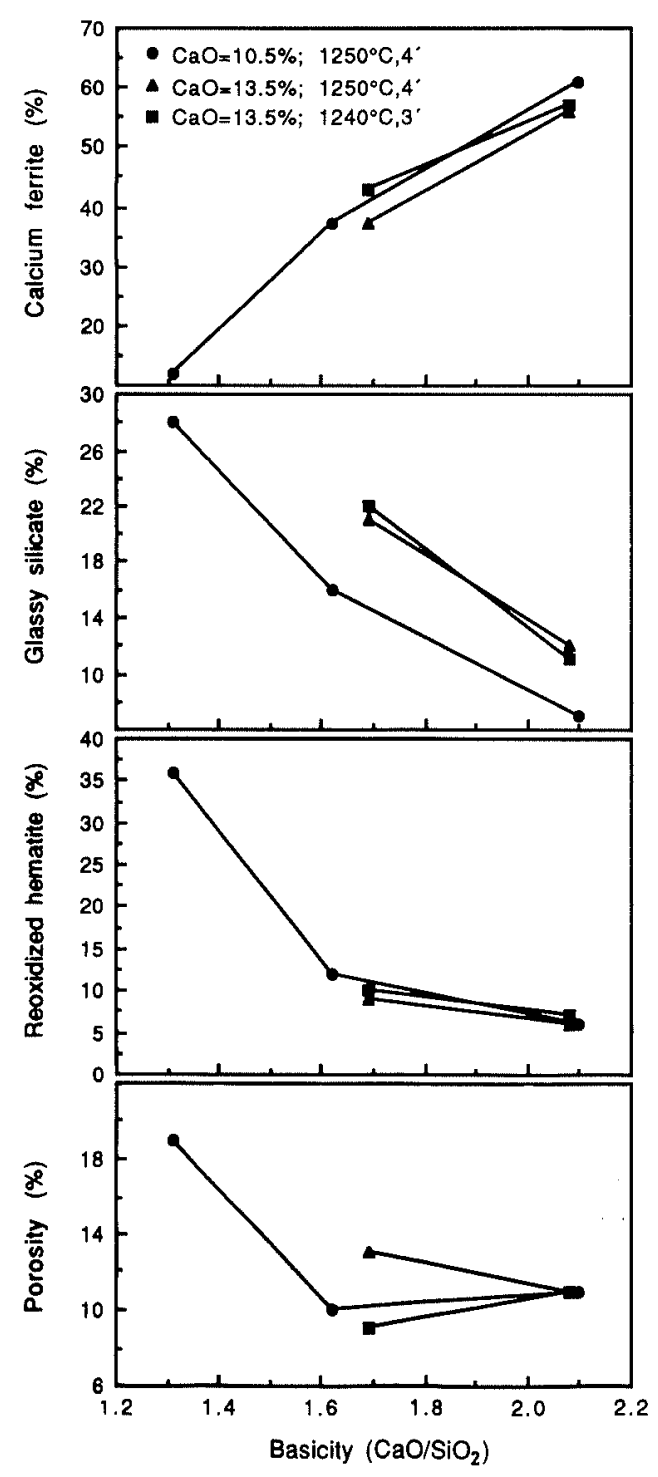

$3^{\prime}, 4^{\prime}$ : Heating time $3 \mathrm{~min}, 4 \mathrm{~min}$

Fig. 3. Effect of basicity $\left(\mathrm{CaO} / \mathrm{SiO}_{2}\right)$ on proportions of phases in the bond. The bonds have the same levels of $\mathrm{Al}_{2} \mathrm{O}_{3}(3.0 \%)$, and $\mathrm{MgO}(0.1 \%)$. 
increase in the amount of calcium ferrite was produced as the basicity increased the minimum amount of calcium ferrite being just greater than $10 \%$ and the maximum being between 50 and $60 \%$. The increase in calcium ferrite was accompanied by a decrease in the amount of glassy silicate from above 25 to below $10 \%$. Interestingly the amount of silicate was greater at a given basicity in the specimens with higher $\mathrm{CaO}$ content; the decrease in silicate with increase in basicity was again approximately linear. The other changes were in the reoxidized hematite which decreased from about 35 to less than $10 \%$ as the basicity increased. This variation was not linear and the decrease was steeper at low basicities. Porosity also decreased as the basicity increased but this was only found over a limited range at low basicity; at high basicities the

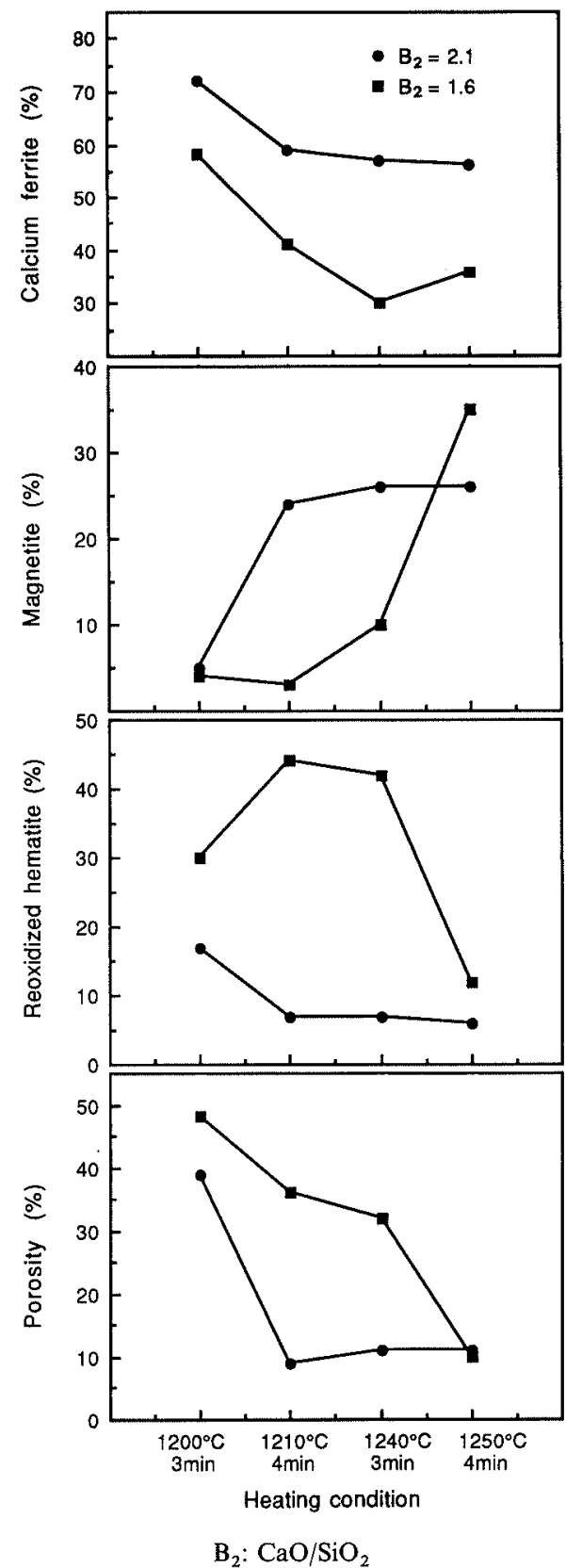

Fig. 4. Effect of heating condition and basicity $\left(\mathrm{CaO} / \mathrm{SiO}_{2}\right)$ on proportions of phases in the bond. The bonds contain the same levels of $\mathrm{SiO}_{2}(6.5 \%), \mathrm{Al}_{2} \mathrm{O}_{3}$ $(3.0 \%)$, and $\mathrm{MgO}(0.1 \%)$. porosity was approximately constant. All these observation were made at a constant level of $3.0 \% \mathrm{Al}_{2} \mathrm{O}_{3}$ and $0.1 \% \mathrm{MgO}$ and at temperatures of either 1240 or $1250^{\circ} \mathrm{C}$.

The influence of basicity at different temperatures on the phase proportions is quite complex and is shown in Fig. 4. This shows the effect of two levels of basicity 1.6 and 2.1 over the temperature range 1200 to $1250^{\circ} \mathrm{C}$ upon the phase proportions. The levels of $\mathrm{SiO}_{2}, \mathrm{Al}_{2} \mathrm{O}_{3}$ and $\mathrm{MgO}$ have been kept constant. The proportion of calcium ferrite tends to drop as the temperature is increased with higher levels of calcium ferrite being associated with the higher basicity. Magnetite increases as the temperature increases with the greater difference found at the lower basicity. For reoxidized hematite at high basicity there is a steady decrease with increase in temperature but at lower basicity the maximum reoxidized hematite is found at an intermediate temperature. At both levels of basicity the porosity decreases with increase in temperature. The higher basicity can reduce the porosity to a low level at a lower temperature.

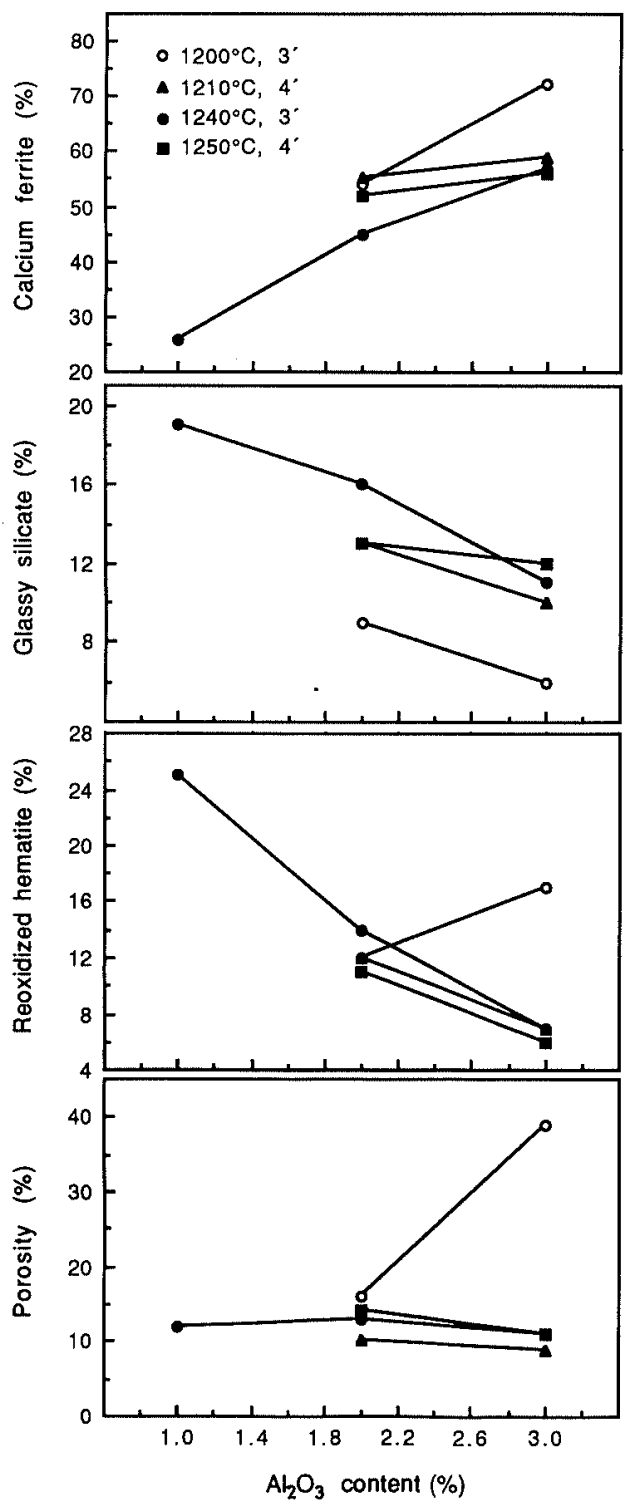

Fig. 5. Effect of $\mathrm{Al}_{2} \mathrm{O}_{3}$ content on proportions of phases in the bond. The bonds have the same levels of $\mathrm{CaO}$ $(13.5 \%), \mathrm{SiO}_{2}(6.5 \%)$, and $\mathrm{MgO}(0.1 \%)$. 


\subsection{Effect of Alumina Content on Mineral Phases}

Three levels of alumina were investigated ranging from 1 to $3 \%$. A range of temperatures was also used. The phase proportions obtained as a function of alumina content are shown in Fig. 5. The amount of calcium ferrite increases as the alumina increases, but at a somewhat different rate in different specimens. Glassy silicate decreases as the alumina increases but the proportional change is much smaller than for the

Table 2. Effect of $\mathrm{Al}_{2} \mathrm{O}_{3}$ content and sintering temperature on mineral compositions of the bonds during the heating stage.

\begin{tabular}{|c|c|c|c|c|}
\hline \multirow{3}{*}{ Phases } & \multicolumn{4}{|c|}{ Specimens } \\
\hline & $1180^{\circ} \mathrm{C}$ & $1210^{\circ} \mathrm{C}$ & I $180^{\circ} \mathrm{C}$ & $1210^{\circ} \mathrm{C}$ \\
\hline & \multicolumn{2}{|c|}{$\mathrm{Al}_{2} \mathrm{O}_{3}=3.0 \%$} & \multicolumn{2}{|c|}{$\mathrm{Al}_{2} \mathrm{O}_{3}=2.0 \%$} \\
\hline $\begin{array}{l}\text { Unreacted } \\
\text { hematite }(\%)\end{array}$ & 6 & 0 & 5 & 1 \\
\hline Magnetite (\%) & 18 & 50 & 15 & 54 \\
\hline Calcium ferrite $(\%)$ & 69 & 35 & 75 & 24 \\
\hline Glassy silicate (\%) & 2 & 15 & 2 & 21 \\
\hline Relict flux (\%) & 5 & 0 & 3 & 0 \\
\hline Porosity (\%) & 51 & 21 & 48 & 5 \\
\hline
\end{tabular}

* The specimens were heated for $4 \mathrm{~min}$ to 1180 or $1210^{\circ} \mathrm{C}$ and then cooled rapidly in nitrogen. The bonds have the same levels of basicity $\left(\mathrm{CaO} / \mathrm{SiO}_{2}=2.1\right)$ and $\mathrm{MgO}(0.1 \%)$.

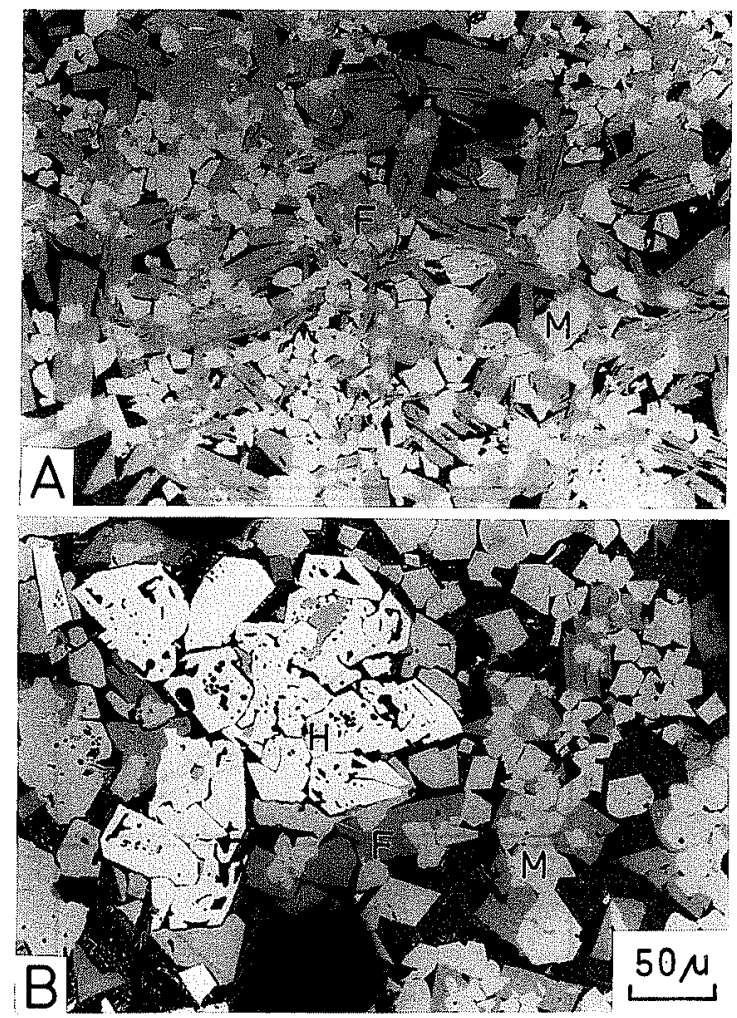

(A) $\mathrm{Al}_{2} \mathrm{O}_{3}=3.0 \%$

(B) $\mathrm{Al}_{2} \mathrm{O}_{3}=1.0 \%$

$\mathrm{H}$ : Reoxidized hematite $\mathrm{M}$ : Magnetite F: Calcium ferrite

Fig. 6. Effect of $\mathrm{Al}_{2} \mathrm{O}_{3}$ content on the formation of reoxidized hematite during the cooling stage of sintering. The specimens were heated for $4 \mathrm{~min}$ to $1255^{\circ} \mathrm{C}$ in the gas mixture $\mathrm{O}_{2}=1 \%, \quad \mathrm{~N}_{2}=99 \% \quad\left(P_{\mathrm{O}_{2}}=\right.$ $\left.\mathrm{I} \times 10^{-2} \mathrm{~atm}\right)$ and then cooled slowly in the same gas mixture as heating. The bonds have the same levels of $\mathrm{CaO}(13.5 \%), \mathrm{SiO}_{2}(6.5 \%)$, and $\mathrm{MgO}(0.1 \%)$. calcium ferrite. Less silicate is found at low temperatures. Reoxidized hematite also generally decreases with an increase in alumina, again the overall change is less than for the calcium ferrite although at low temperature there is an increase in reoxidized hematite with increase in alumina. There only appears to be an effect of alumina on porosity in the specimens held at the lowest temperature and this gives a rapid rise in porosity as the alumina is increased. The influence of the alumina content in the overall sintering cycle is quite complicated but the effects of alumina on the phases produced at low temperatures during heating can be seen from specimens that were rapidly quenched in nitrogen. This information is in Table 2 from which it is seen that at very low temperatures there is a large amount of calcium ferrite formed in a very porous matrix at $1180^{\circ} \mathrm{C}$. Heating further to $1210^{\circ} \mathrm{C}$ dramatically reduces the amount of calcium ferrite which is replaced by magnetite and glassy silicate with an associated reduction in the porosity. The lower level of alumina leads to higher magnetite and silicate levels and a very much lower level of porosity at the higher temperature.

There is a further effect of alumina on the formation of reoxidized hematite during the cooling of sintering which may be seen in Fig. 6. Figure 6(A) shows a sample that has been heated to $1255^{\circ} \mathrm{C}$ in an atmosphere with oxygen partial pressure of $1 \times 10^{-2}$ atmospheres

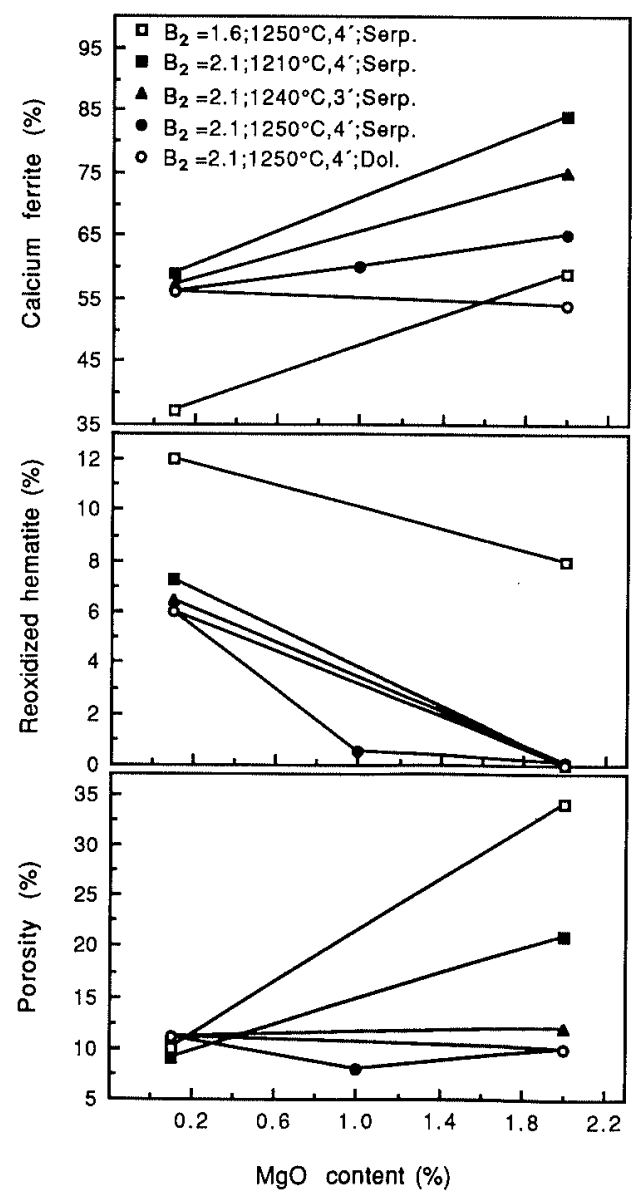

Fig, 7. Effect of MgO content on proportions of phases in the bond. The $\mathrm{MgO}$ content is increased by the addition of serpentine or dolomite. All bonds contain the same levels of $\mathrm{SiO}_{2}(6.5 \%)$, and $\mathrm{Al}_{2} \mathrm{O}_{3}(3.0 \%)$. 
( $1 \% \mathrm{O}_{2}$ and $99 \% \mathrm{~N}_{2}$ ) and then slowly cooled in the same atmosphere. There is no reoxidized hematite in this sample which has an alumina content of $3 \%$. A similar sample but with alumina at a $1 \%$ level subjected to the same thermal cycle contains a significant amount of reoxidized hematite in the microstructure, as shown in Fig. 6(B). It seems then that increase in alumina reduces the formation of reoxidized hematite during the conventional cooling of sinter.

\subsection{Effect of Magnesia on Mineral Phases}

Serpentine and dolomite were both used as sources of magnesia in this work. The effect of increasing magnesia on the proportion of mineral phases in sinter
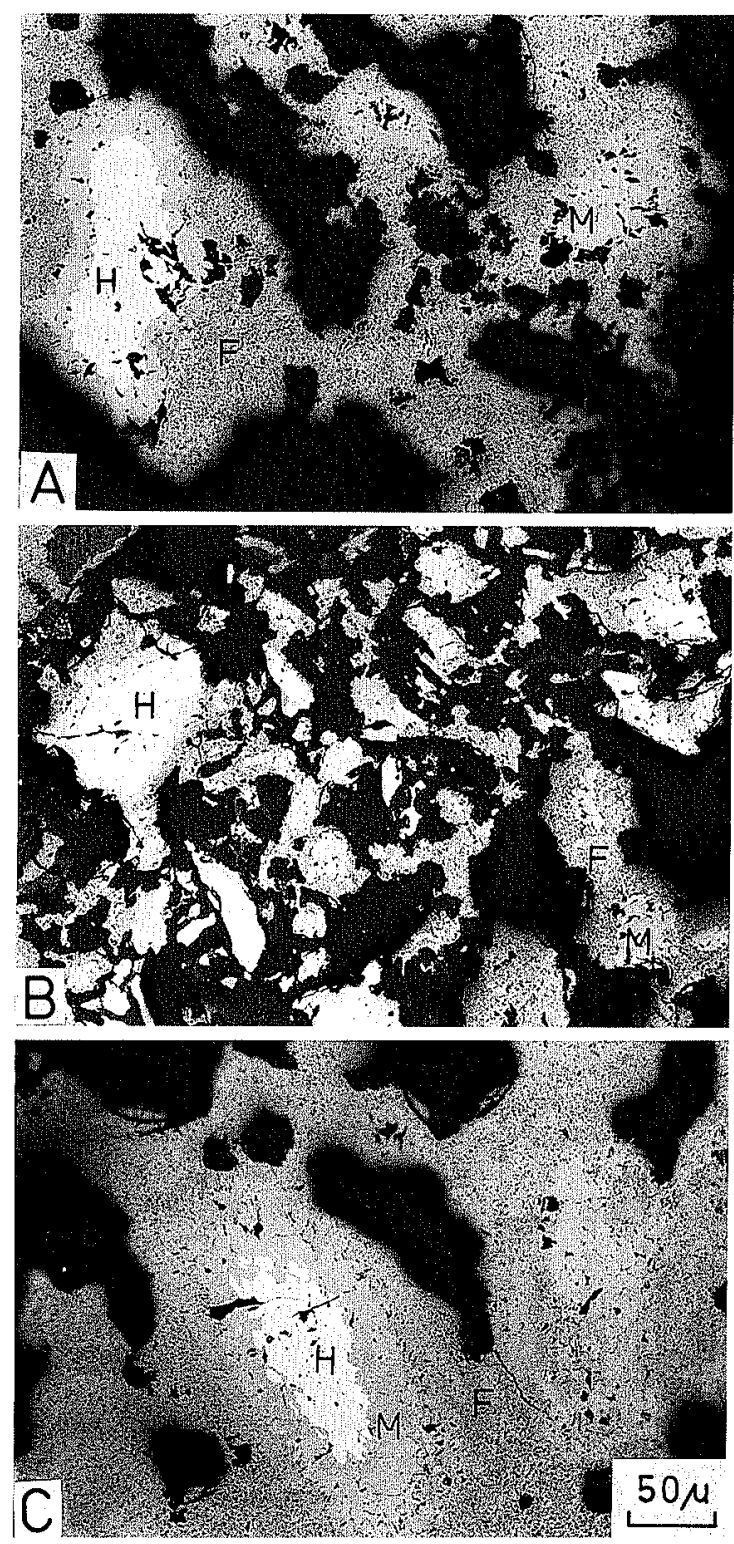

(A) $\mathrm{MgO}=0.1 \%, \mathrm{Al}_{2} \mathrm{O}_{3}=3 \%$

(B) $\mathrm{MgO}=2.0 \%, \mathrm{Al}_{2} \mathrm{O}_{3}=3 \%$

(C) $\mathrm{MgO}=0.1 \%, \mathrm{Al}_{2} \mathrm{O}_{3}=2 \%$

$\mathrm{H}$ : Unreacted hematite $\mathrm{M}$ : Magnetite

F: Calcium ferrite

Fig. 8. Effect of $\mathrm{MgO}$ content on microstructure of the bond at a very low sintering temperature during the heating stage. The specimens were heated for $4 \mathrm{~min}$ to $1180^{\circ} \mathrm{C}$ and then cooled rapidly in nitrogen. The bonds have the same levels of $\mathrm{CaO}(13.5 \%)$, and $\mathrm{SiO}_{2}(6.5 \%)$. is shown in Fig. 7. The proportion of calcium ferrite increases with increase in magnesia under most experimental conditions although the effect is less at high temperatures and high basicities. The increase in magnesia remarkedly reduces the proportion of reoxidized hematite, which may under some conditions be totally suppressed. The porosity under some conditions increases with increase in magnesia content.

Although the influence of magnesia does not appear to be quite as complex as that of alumina it has a role both during the heating of the sinter and during the subsequent cooling. In the initial stages of sinter formation at $1180^{\circ} \mathrm{C}$ increase in magnesia retards the reaction that produces calcium ferrite, Fig. 8. After heating to $1240^{\circ} \mathrm{C}$ followed by rapid quenching the increase in the amount of magnesia from 0.1 to $2.0 \%$ by addition of serpentine dramatically reduces the amount of calcium ferrite, as is shown in Fig. 9. The dominant phase at high magnesia contents is magnetite. During cooling, even slow cooling in an atmosphere of oxygen, the magnetite is not oxidized to hematite when the magnesia content is high. The magnetite may however be converted into calcium ferrite on cooling under oxidizing conditions and the kinetics of this reaction seem to depend on whether the magnesia is added as dolomite or as serpentine.

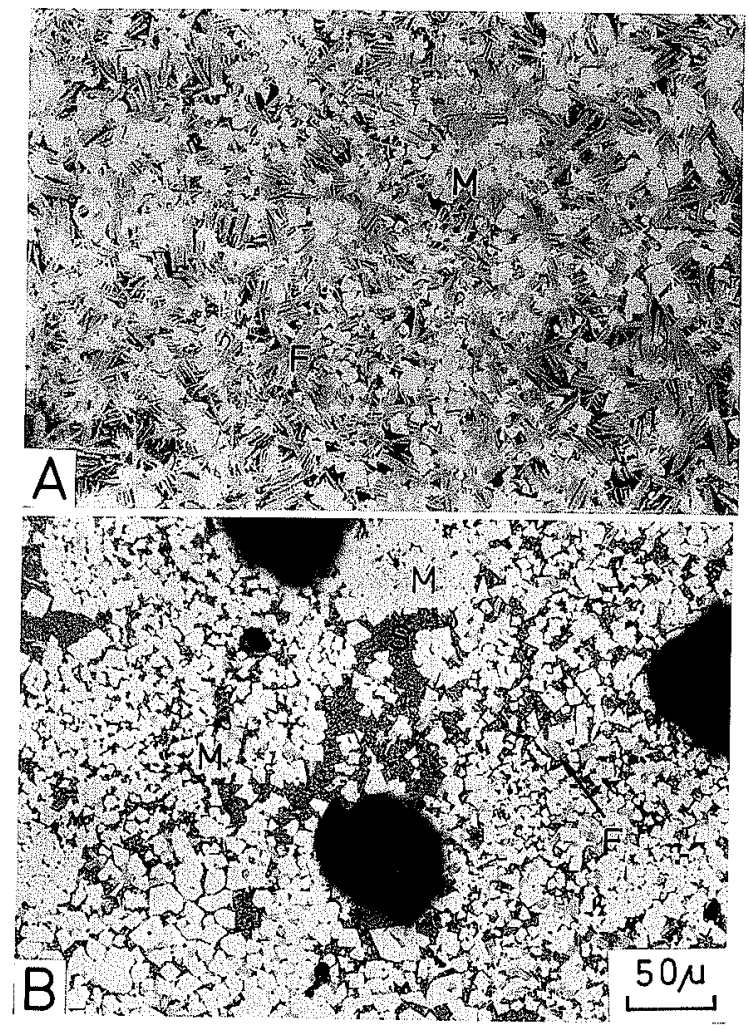

(A) $\mathrm{MgO}=0.1 \%$

(B) $\mathrm{MgO}=2.0 \%$

M: Magnetite C: Calcium ferrite S: Glassy silicate

Fig. 9. Effect of $\mathrm{MgO}$ content on the formation of minerals during the heating stage. The specimens were heated for $3 \mathrm{~min}$ to $1240^{\circ} \mathrm{C}$ in the standard gas mixture $\left(\mathrm{CO}=1 \%, \mathrm{CO}_{2}=24 \%\right.$, and $\mathrm{N}_{2}=75 \%$ ) and then cooled rapidly in nitrogen. The bonds have the same levels of $\mathrm{CaO}(13.5 \%), \mathrm{SiO}_{2}(6.5 \%)$, and $\mathrm{Al}_{2} \mathrm{O}_{3}$ $(3.0 \%)$. 


\subsection{Effect of Ores on Mineral Phases}

Tablets were made from six different ores to give sinter specimens with a range of basicities from 1.3 to 2.1 but with fixed content of alumina (3.0\%) and magnesia $(0.1 \%)$. These were then sintered in the standard atmosphere at several different temperatures. The results of these experiments are shown in Fig. 10. Comparing the tests performed at $1210^{\circ} \mathrm{C}$ (SM2 \& SM3) it is seen that the major factor influencing the phase proportions is the basicity. At a basicity of 2.1 the predominant phase is calcium ferrite, there is only a limited amount of reoxidized hematite and a significant amount of magnetite. In these experiments the effect of ore type is very slight, but the porosity of the bond varies with the type of ore used in a range from 6 to $21 \%$. The lower basicity of 1.6 produces a very much greater amount of reoxidized hematite and a reduced amount of calcium ferrite and almost no magnetite and a considerably higher porosity (around 35\%), again the effect of ore type is slight. At this same basicity of 1.6 holding at a higher temperature $1250^{\circ} \mathrm{C}$ (SM1) gives much the same amount of calcium ferrite, but much less reoxidized hematite oxidized from the magnetite and much lower porosity. Again, the porosity varies with the type of ore used. In this case the ore type is significant in that the specimen made from ore $\mathrm{F}$ which was itself is a coarse dense hematite contains more unreacted hematite. The influence of ore type is more noticeable in the specimens of basicity 1.6 held at $1240^{\circ} \mathrm{C}$ (SM4) the different ores produce a difference in the proportions of magnetite and reoxidized hematite. The most noticeable effect being for ore $\mathrm{E}$ which has a small amount of reoxidized hematite oxidized from the magnetite. This ore is different in type than the others in that it is limonitic. The same effect is seen at a basicity of 1.3 held at a temperature of $1250^{\circ} \mathrm{C}$ (SM5) in these specimens there is very little calcium ferrite and significantly more silicate than in any of the other specimens. Again ore $\mathrm{E}$ produces much less reoxidized hematite than do the other ores.

\subsection{Effect of $\mathrm{Al}_{2} \mathrm{O}_{3}$ and $\mathrm{MgO}$ on Mineral Phases and Properties of Industrial Sinters}

The work done on small tablet specimens has been expanded to a commercial scale by the use of sinter pot tests. Iron ores, limestone, serpentine, dolomite, silica sand, $\mathrm{Al}_{2} \mathrm{O}_{3}$ powder and coke were mixed and sintered in a $400 \mathrm{~mm} \times 400 \mathrm{~mm}$ sinter pot to study the effects of $\mathrm{MgO}$ and $\mathrm{Al}_{2} \mathrm{O}_{3}$ on the phase distribution and the sinter properties. For the alumina work the sinters all had the same proportions of $\mathrm{CaO}(9.5 \%), \mathrm{SiO}_{2}(5.5 \%)$ and $\mathrm{MgO}(1.9 \%)$. Three different ores were used and in one (ore $\mathrm{C}$ ) the magnesia was added as serpentine but in all the others dolomite was used. The results are to be found in Fig. 11. There is a clear trend for the calcium ferrite to increase with alumina increases as found in the reacted tablets the absolute amounts of calcium ferrite are somewhat lower in these industrial sinters. The hematite both total and reoxidized decreases as the alumina increases. Again the trend of reoxidized hematite is similar to the tablet specimens. The serpentine containing specimens show the same trends but contain higher amounts of calcium ferrite. The sinters made from ore B contain lower amounts of calcium ferrite and total hematite but more reoxidized hematite. The porosity found in the pot tests is generally higher than that in the tablets and for ores C and D sintered with a low coke rate there is a slight increase in porosity as the alumina increases. For ore B sintered with a high coke rate the porosity is greater and the porosity is reduced slightly as the alumina content increases.

The pot tests provided sufficient sinter to perform the standard sinter property tests. The tumbler index test showed a clear trend to reduce the index as the alumina increased; the serpentine containing sinters (ore $\mathrm{C}$ ) showed the higher index. The trend in the RDI (reduction degradation index) test was not so clear and the ore type made a great difference. The ore made with serpentine, ore $\mathrm{C}$, showed a remarkable increase in RDI with increase in alumina and ore $\mathrm{D}$ showed a less

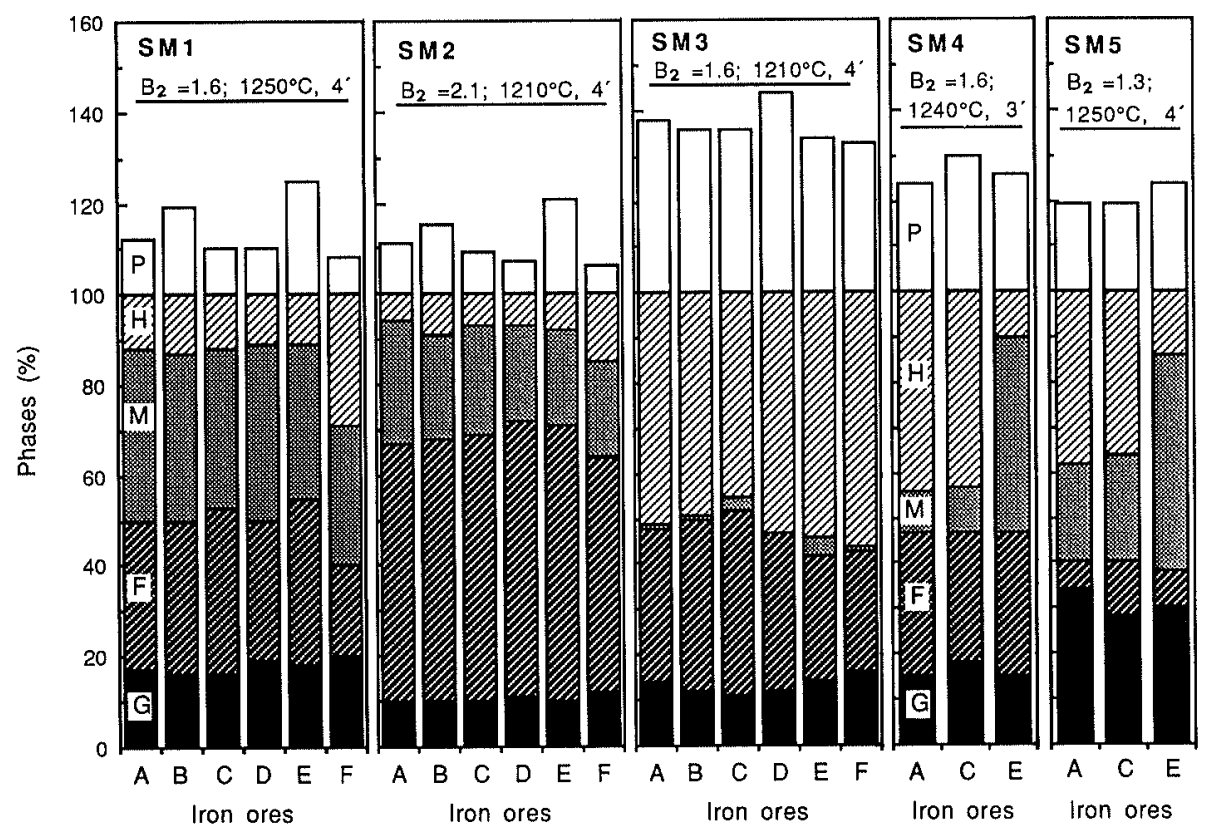

SM1 to SM5: Experimental serial number

$\mathrm{B}_{2}: \mathrm{CaO} / \mathrm{SiO}_{2}$

$3^{\prime}, 4^{\prime}$ : Heating time $3 \mathrm{~min}, 4 \mathrm{~min}$

P: Porosity

M: Magnetite

F: Calcium ferrite

G: Glassy silicate

$\mathrm{H}$ : Reoxidized hematite, except ore $\mathrm{F}$ bond containing some unreacted hematite

Fig. 10.

Effect of iron ore on proportions of phases in the bond. The bonds have the same levels of $\mathrm{Al}_{2} \mathrm{O}_{3}(3.0 \%)$ and $\mathrm{MgO}$ $(0.1 \%)$. 

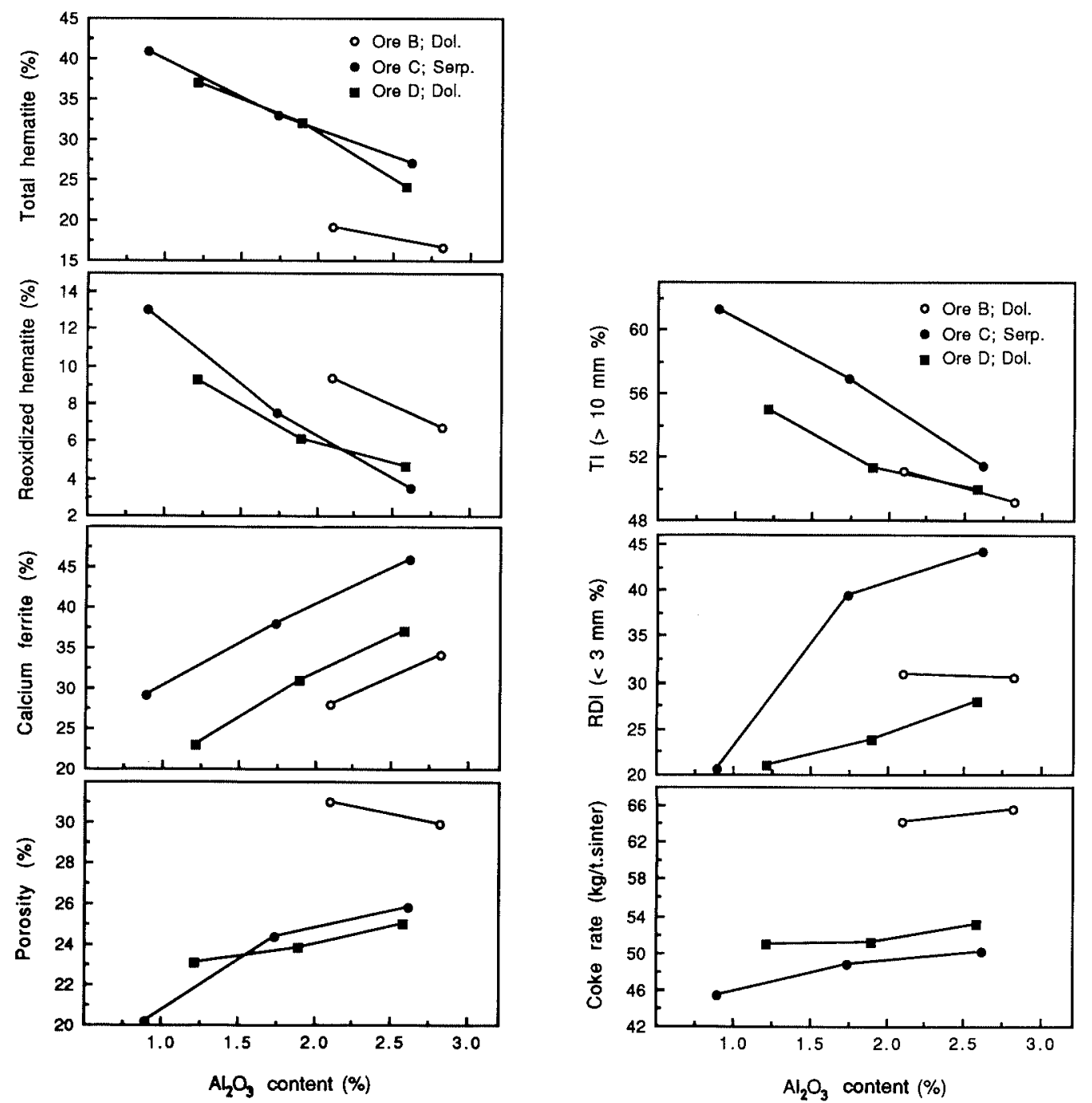

Fig. 11. Effect of $\mathrm{Al}_{2} \mathrm{O}_{3}$ content on phases and properties of the commercial sinter. All sinters have the same levels of $\mathrm{CaO}(9.5 \%), \mathrm{SiO}_{2}(5.5 \%)$, and $\mathrm{MgO}(1.9 \%)$. The ore $\mathrm{C}$ sinters were added by serpentine as the source of $\mathrm{MgO}$ constituent. The others were added by dolomite.

marked tendency to increase RDI with increase in alumina. The ore $B$ had an approximately constant RDI at two levels of alumina. There was a slight tendency for the coke rate to increase with increase in alumina but differences in ore type were significant with ore $\mathrm{B}$ again showing a difference in that a much higher coke rate was required. The ore made with serpentine, ore $\mathrm{C}$, required the lowest coke rate.

To investigate the effect of $\mathrm{MgO}$ on pot sinters, ore $\mathrm{C}$ was used and the $\mathrm{MgO}$ was added in the form of serpentine and this contained an alumina content of $0.9 \%$. An ore mixture was also used and in this case the magnesia was added in the form of dolomite and the alumina content was $2.4 \%$. For both mixes the $\mathrm{CaO}$ $(9.5 \%)$ and the $\mathrm{SiO}_{2}(5.5 \%)$ were kept constant.

The effect of variation of $\mathrm{MgO}$ on the phase proportions is shown in Fig. 12. The amount of total and reoxidized hematite both decrease as the $\mathrm{MgO}$ content is increased. The absolute levels for the two ores are quite different, but this almost certainly reflects the difference in alumina content in the two mixes. The trend of reoxidized hematite is the same as that found in the tablet experiments but the reoxidized hematite levels in the pot sinters are higher. There is very much less calcium ferrite in the pot sinters but the trends are the same as in the tablet experiments in that in the ore with serpentine the amount of calcium ferrite increases, whilst in that with dolomite it decreases slightly with increase in magnesia. The porosity was unaffected by variation in magnesia with the low alumina containing ore $\mathrm{C}$ having the lower porosity.

The tumbler index was slightly reduced for both ores with increase in magnesia. The dolomite containing ore showed a more marked tendency and the serpentine containing ore with a lower alumina had a significantly greater tumbler index. The RDI variation with magnesia depends on the magnesia source. With the serpentine containing ore there was an approximately constant value of RDI at both levels of magnesia that were tested. The dolomite containing ore with a higher alumina gave higher values of RDI at all magnesia levels and the RDI decreased as the magnesia was increased. The coke rate increased slightly with increase in magnesia for both ores, but in this case the serpentine containing ore with a lower alumina always required a lower coke rate. Again the dolomite containing ore showed a more marked tendency. 

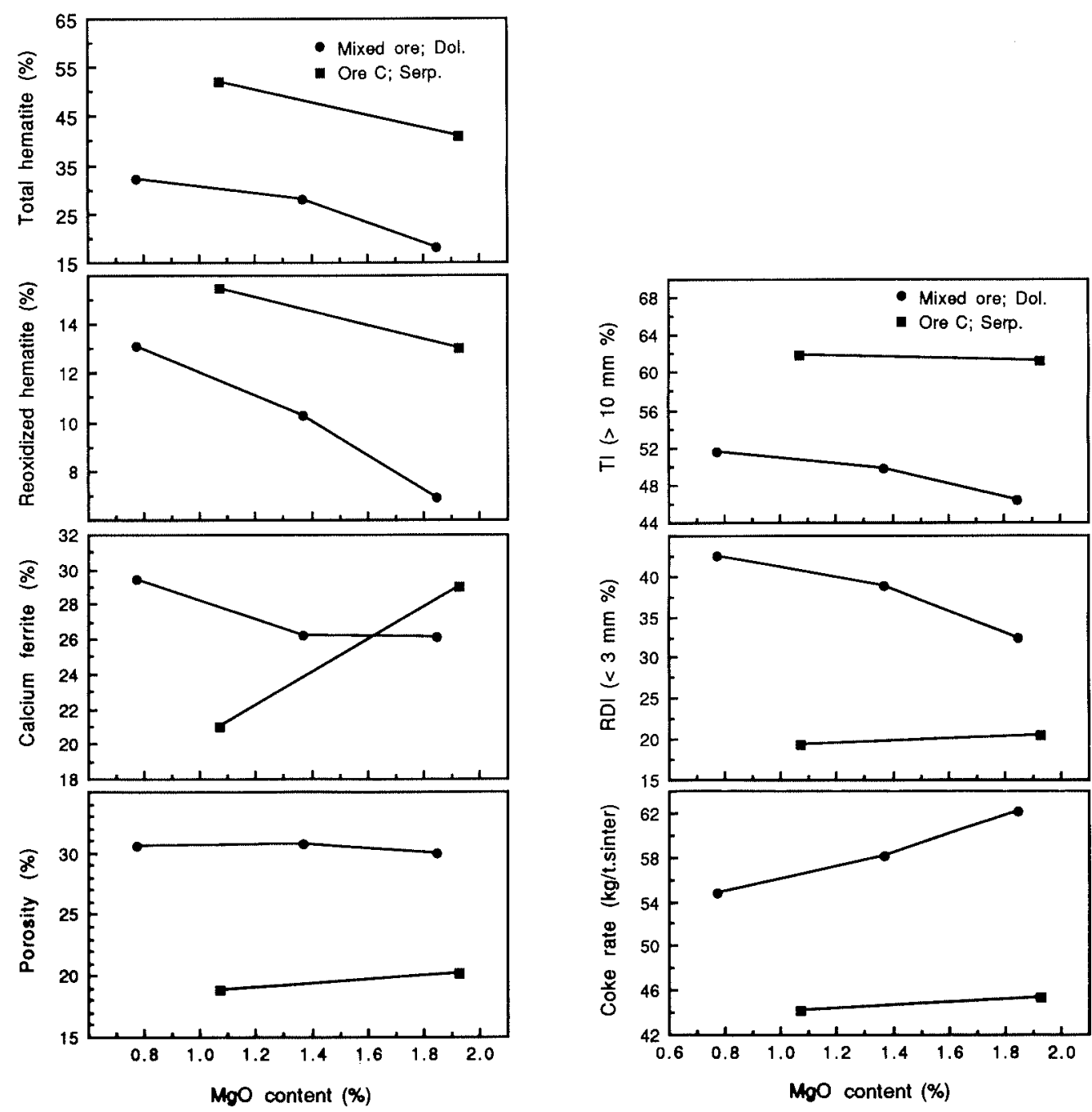

Fig. 12. Effect of $\mathrm{MgO}$ content on phase and properties of the commercial sinter. The sinters made from mixed ores (ore $\mathrm{A} 25 \%$, ore $\mathrm{B} 50 \%$, and ore $\mathrm{C} 25 \%$ ) have the same levels of $\mathrm{CaO}(9.5 \%), \mathrm{SiO}_{2}(5.5 \%$ ), and $\mathrm{Al}_{2} \mathrm{O}_{3}(2.4 \%)$; the $\mathrm{MgO}$ content is increased by adding dolomite. The sinters made from ore $\mathrm{C}$ have the same levels of $\mathrm{CaO}(9.5 \%), \mathrm{SiO}_{2}(5.5 \%)$, and $\mathrm{Al}_{2} \mathrm{O}_{3}(0.9 \%)$; the $\mathrm{MgO}$ content is increased by adding serpentine.

\section{Discussion}

Previous experimental work carried out in air showed that the amount of calcium ferrite increased with basicity and $\mathrm{Al}_{2} \mathrm{O}_{3}$ content. ${ }^{1-4)}$ The same trends were found in this work. It was also recognized that $\mathrm{MgO}$ could retard the oxidation of magnetite to hematite in sinter ${ }^{7)}$ a finding which is also confirmed in this work. The present work has however focussed on the different roles of additions on heating under a reducing atmosphere and on cooling under an oxidizing atmosphere. When these individual steps are considered the effect of alumina and magnesia additions contrast markedly.

\subsection{Initial Reactions on Heating of Sinter}

The initial reaction on heating a sinter mix under a reducing atmosphere appears to be the formation of a calcium ferrite by reaction between lime and hematite. ${ }^{6}$ It has been proposed that the presence of alumina both initiates the formation of the calcium ferrite and stabilizes it. ${ }^{4)}$ Investigation of the ternary phase diagram $\mathrm{Al}_{2} \mathrm{O}_{3}-\mathrm{CaO}-\mathrm{Fe}_{2} \mathrm{O}_{3}$ by Lister and Glasser ${ }^{8)}$ showed that at a constant $\mathrm{CaO}$ content (e.g. 13.5\%) an increase in $\mathrm{Al}_{2} \mathrm{O}_{3}$ increased the dissociation temperature of ternary calcium ferrite thus making the phase more stable. In the quaternary phase diagram $\mathrm{CaO}-\mathrm{SiO}_{2}-\mathrm{Al}_{2} \mathrm{O}_{3}-\mathrm{Fe}_{2} \mathrm{O}_{3}$ Inoue et al. ${ }^{9}$ ) showed that the incongruent melting temperature of quaternary calcium ferrite increased with increase in alumina content at a constant $\mathrm{CaO}$ and $\mathrm{SiO}_{2}$ content. This is important because the next reaction on heating of a sinter mix under reducing conditions is the reaction of calcium ferrite to produce magnetite and the silicate melt, this occurs at a higher temperature than that at which the calcium ferrite forms for any given low oxygen potential ${ }^{6)}$ and is also the most important reaction in reducing the porosity of the sinter. The balance of these two reactions is clearly a delicate one. At low partial pressures of oxygen the tendency to produce the more reduced structure of magnetite and the silicate melt is very great and may be more important than the tendency of alumina to stabilize calcium ferrite.

There is a clear trend to increase the amount of calcium ferrite in simulated sinter specimens with 
increase in alumina. However, at the $2 \%$ alumina level there is more calcium ferrite and slightly less porosity present at low temperature e.g. $1180^{\circ} \mathrm{C}$, Table 2 and Fig. $8(\mathrm{C})$, than in a specimen with $3 \%$ alumina when the mixture has been heated in nitrogen. The same effect is seen at the end of the sintering cycle in Fig. 5 where the level of calcium ferrite in the specimens heated to $1200^{\circ} \mathrm{C}$ is always higher than in those heated to $1240^{\circ} \mathrm{C}$. At the low temperature of $1180^{\circ} \mathrm{C}$ in nitrogen the $2 \%$ level of alumina produces the most extensive reaction to calcium ferrite and by contrast the amount of reaction produced by the increase in magnesia to $2 \%$ is minimal.

The initial reaction when the magnesia level is high is probably influenced by the possible reaction between $\mathrm{MgO}$ and hematite. This can lead to the formation of magnesio-ferrite starting at very low temperatures in the region of $1000^{\circ} \mathrm{C}_{;}^{10}$ ) this could retard the formation of calcium ferrite. This will mean that the bond in the sinter with a high magnesia content will tend to be more porous as it is the reaction to form calcium ferrite and the dissociation of the ferrite to magnetite and the silicate melt that fills the spaces between the initial ore particles.

If a magnesia rich mixture is heated up to a higher temperature of $1240^{\circ} \mathrm{C}$ in the standard gas mixture and then cooled rapidly, very much more silicate and magnetite formed than would be the case with the more usual low magnesia level. It is clear therefore that in such material a large proportion of the calcium ferrite found in the final sinter must form during cooling in an oxidizing environment.

\subsection{Reactions during Cooling of Sinter}

At a high temperature under a reducing atmosphere the sinter mix will react to convert much of the calcium ferrite to magnetite and the silicate melt in the heating stage. On cooling such a mix in air, as is normal in sintering, a variety of reactions are possible. Magnetite and the silicate melt may combine with some of the oxygen to give calcium ferrite. Alternatively the magnetite may itself be oxidized to produce hematite. Again different constituents in the sinter affect these reactions differently.

Alumina has an influence on the formation of reoxidized hematite on cooling in that at a low alumina level of $1 \%$ a considerable proportion of reoxidized hematite is found on cooling under the standard gas mixture used for the heating experiments. At a level of $3 \%$ alumina very much less reoxidized hematite is formed and the major phase is calcium ferrite. This overall trend is seen in Figs. 5 and 11 but in the latter figure it is seen that the reduction in the amount of total hematite with increase in alumina is mainly due to the reduction in reoxidized hematite.

When the level of magnesia is altered the amount of reoxidized hematite is reduced as the magnesia level is increased. In the tablet firing experiments the amount of reoxidized hematite may be reduced to zero by increase in magnesia. In the pot sinters more reoxidized hematite is produced and this probably reflects a different balance of reactions during heating of the sinter.

\subsection{Factors Influencing the Stability of Individual Phases}

The experiments discussed above indicate that the regimes of reaction; phase formation and reaction during heating under a reducing atmosphere and the further phase reactions produced during cooling in an oxidizing atmosphere both contribute to the final microstructure of the sinter. The individual compounds alumina and magnesia influence the two regimes in different ways. Comparison of the simulated sintering of the ores with a basicity of 1.6 indicates that in the final sinter after heating to $1210^{\circ} \mathrm{C}$ for all the ores used the major phases present are reoxidized hematite typically of the order of $50 \%$, calcium ferrite typically of the order of $30 \%$ and about $15 \%$ of glassy silicate. There is also a very considerable amount of porosity of the order to $35 \%$, and the pores are open in type. From the observation of microstructure, the reoxidized hematite is present not only near the surface but also inside the specimen in associate with open pores. This suggests that in this case the formation of calcium ferrite from the reaction on heating between hematite and flux and the dissociation of calcium ferrite into magnetite and the silicate melt is not sufficient to fill the spaces between initial ore particles. This porous structure contains a large amount of magnetite (produced from calcium ferrite and reduced from hematite ore particles directly), some undissociated calcium ferrite and the silicate melt. During cooling, air penetrates through the open pores providing a high oxygen potential in this structure. Magnetite is almost entirely oxidized to hematite, except some of it reacts with the silicate melt to form calcium ferrite. Thus a large amount of reoxidized hematite is produced. When the same ore mixtures are heated to the higher temperature $1250^{\circ} \mathrm{C}$, more silicate melt is produced from the dissociation of calcium ferrite; the porosity is considerably reduced and the pores are closed. During the cooling in air, the oxidation of magnetite is limited to near the surface of specimens. Very much less reoxidized hematite, very much more magnetite and slightly more glassy silicate are produced in the bonds. The change in basicity from 1.6 to 2.1 after heating to $1210^{\circ} \mathrm{C}$ markedly increases the amount of calcium ferrite to about $60 \%$. The amount of reoxidized hematite is limited to about $10 \%$ as is the glassy silicate and there is about $20 \%$ of magnetite. With this higher basicity the porosity is very much reduced and the pores are closed despite the low heating temperature and is of the order of $10 \%$.

Reduction of the basicity to 1.3 and heating at $1250^{\circ} \mathrm{C}$ almost totally removes the calcium ferrite and the proportions of magnetite and reoxidized hematite then depend critically on the type of original ore with the limonitic ore $\mathrm{E}$ giving a much greater ratio of magnetite to reoxidized hematite. This same effect is found at the basicity of 1.6 after heating at $1240^{\circ} \mathrm{C}$ in which case the limonitic ore contains considerably less 
hematite oxidized from magnetite. It is observed that although the limonitic ore has a similar proportion of porosity to that of other ores reacted under similar conditions, the pores in this case tend to be closed. Such closed pores may well prevent the reoxidation of magnetite on cooling in an oxidizing atmosphere. The limonitic ore appears to be more easily fused than a hematite ore and produces a closed pore structure at lower sintering temperatures.

\subsection{Relationship between Sinter Structure and Pro- perties}

The conventional wisdom is that the RDI increases with the amount of reoxidized hematite in the sinter as it is controlled by the transformation of hematite to magnetite during reduction at a temperature around $550^{\circ} \mathrm{C}^{1{ }^{1)}}$ In the sinter pot tests the RDI does seem to increase with reduction in the amount of reoxidized hematite if the experiments in which the alumina was varied are considered. The same is not true in the experiments in which magnesia is changed at constant alumina. The RDI does however seem to relate well to the change in reoxidized hematite. As a high porosity in sinter may promote the transformation of hematite to magnetite during reduction, the RDI would seem to be related to the change in porosity in the same ore sinters that had a variation in alumina. Another factor that possibly influences the RDI is the ease with which cracks grow in individual minerals in the sinter bond. There was some evidence that as the alumina content of certain sinters increases the RDI increases. ${ }^{12-14)} \mathrm{A}$ Vickers hardness tester was used to check this observation in the present work in ore $\mathrm{C}$ sinters. Using a $1 \mathrm{~kg}$ load the impression of the hardness indenter in the sinter bond increased in size with increase in $\mathrm{Al}_{2} \mathrm{O}_{3}$ content. Tumbler strength tests also showed that the mechanical strength of sinter decreased with increase in $\mathrm{Al}_{2} \mathrm{O}_{3}$ content. This lower strength combined with the increase in porosity is a factor associated with the increase in alumina. These two factors counteract the reduction in hematite that accompanies the increase in alumina. The outcome is that there does not appear to be simple relationships between the sinter mineralogy and the mechanical properties. In order to establish such relationships very much more experimental work is necessary in which all the contributory factors are properly measured.

The results obtained from tablet sintering experiments show that the porosity of the sinter bond increases with increase in both alumina and magnesia at a low sintering temperature. The bond made from ore $\mathrm{B}$ is more porous than ore $\mathrm{C}$ and ore $\mathrm{D}$ at a high sintering temperature. The similar trends are found in the sinters made from pot tests. It is also clear that the coke rate increases with increase in both alumina and magnesia. The sinter made from ore $\mathrm{B}$ requires a higher coke rate than ore $\mathrm{C}$ and ore $\mathrm{D}$. Therefore, the densification characteristics of raw material mix for generating the bond seems to relate well to the coke rate in industrial sintering.

\section{Conclusions}

(1) An increase in basicity $\left(\mathrm{CaO} / \mathrm{SiO}_{2}\right)$ favours the formation of calcium ferrite and the densification of the bond at low sintering temperatures.

(2) With increase in the $\mathrm{Al}_{2} \mathrm{O}_{3}$ content the amount of calcium ferrite increases and the amount of glassy silicate decreases. The oxidation potential from magnetite to hematite increases to a higher level on cooling and the amount of reoxidized hematite decreases. The decrease in alumina promotes the formation of the bond at low temperatures during heating of the sintering and thus promotes densification of the bond. Alumina has its most marked effect during the heating of commercial sinter.

(3) $\mathrm{MgO}$ increase, introduced by the addition of dolomite, decreases the amount of calcium ferrite slightly. When $\mathrm{MgO}$ is added in the form of serpentine, the calcium ferrite increases considerably. It does not reduce the porosity as increased $\mathrm{MgO}$ does not promote the formation of the bond at low temperatures during heating. The major effect is to reduce the amount of reoxidized hematite formed on cooling in an oxidizing atmosphere. Magnesia thus has its major influence during the cooling of commercial sinter.

(4) The ore mixes used in this work generally lead to similar mineral compositions of the bond for given sintering conditions. The major exception is when an ore with coarse dense hematite is used, in which case the bond contains some unreacted hematite. The porosity of the bond varies with the type of ore used. Limonitic ore produces a bond with closed pores and less reoxidized hematite at lower temperature and basicity than do hematite ores.

(5) In the sinter pot trials the general influence of alumina and magnesia was found to be similar to that in the tablet sintering. The properties, particularly the RDI of the pot sinter did not vary in a simple way with the variation in phase proportions. This is due to the increase in alumina in the bond resulting in a decrease in the bond strength and probably an increase in the porosity. There are therefore two opposing effects that increase the RDI one is the reduction in the hematite content, the other is the increase in bond strength and the decrease in porosity with reduction in alumina in the bond.

\section{Acknowledgements}

The authors would like to express their appreciation to China Steel Corporation, Taiwan, and Department of Engineering Materials, The University of Sheffield, U.K., for supporting this work.

\section{REFERENCES}

1) Y. Ishikawa, Y. Shimomura, M. Sasaki, Y. Hida and H. Toda: Ironmaking Proc., Vol. 42, AIME, Atlanta, (1983), 17.

2) K. Ito, Y. Hida, M. Sasaki and Y. Shimomura: Trans. Iron Steel Inst. Jpn., 23 (1983), B403.

3) M. Taniguchi, K. Yamaguchi, K. Ito and Y. Hida: Trans. Iron Steel Inst. Jpn., 24 (1984), B70.

4) P. R. Dawson, J. Ostwald and K. M. Hayes: Trans. Inst. Min. Metall., 94 (1985), C71. 
5) L. H. Hsieh and J. A. Whiteman: ISIJ Int., 29 (1989), 24.

6) L. H. Hsieh and J. A. Whiteman: ISIJ Int., 29 (1989), 625.

7) G. S. Vasil'ev, G. G. Efimenko, D. A. Kovalev, E. I. Sulimenko and L. B. Gamazova: Steel USSR, 1 (1971), 415.

8) D. H. Lister and F. P. Glasser: Trans. Brit. Ceram. Soc., 66 (1967), 293.

9) K. Inoue, H. Hayashi, K. Yoshioka and T. Takahashi: R.D Kobe Steel Engineering Reports, 34 (1984), No. 4, 22.

10) B. Phillips, S. Somiya and A. Muan: J. Am. Ceram. Soc., 169
(1961), 44

11) K. Kanisawa, M. Wajima, H. Soma, O. Mikuni and Y. Itoh Tetsu-to-Hagané, 67 (1981), S48.

12) Y. Yamaoka, S. Nagaoka, Y. Yanada and R. Ando: Trans. Iron Steel Inst. Jpn., 14 (1974), 185.

13) F. Matsuno, S. Nishikida and H. Ikesaki: Trans Iron Steel Inst. Jpn., 24 (1984), 1040.

14) F. Matsuno, S. Nishikida and H. Ikesaki: Trans. Iron Steel Inst. Jpn., 25 (1985), 953. 